\section{Upstream approaches to reducing socioeconomic inequalities in health}

\section{Abordagens contracorrente para reduzir iniqüidades socioeconômicas em saúde}

George A. Kaplan, PhD

Professor and Chair

Department of Epidemiology

Director, Center for Social Epidemiology and Population Health

School of Public Health

University of Michigan

109 S. Observatory Street

Ann Arbor, Michigan , USA 48109-2029

gkaplan@umich.edu

To be Presented at Round Table V. V Brazilian Epidemiology Congress, Curitiba, PR, Brazil. March 23-27, 2002.

\section{Introduction}

There are few epidemiologic observations that are as robust as the association between socioeconomic position, measured in a variety of ways, and risk of disease incidence and death ${ }^{1-3}$. The facts are well known:

- the risk of adverse health outcomes increases with a decreasing level of socioeconomic position;

- this relationship is widespread, being found in most places and during most periods of time;

- generally speaking it is found for all age groups;

- it is found for most, with a few exceptions, health outcomes; and

- while theinverse relationship is ubiquitous, the strength of the association varies between groups, places, and over time. It is also clear that there has been an explosion of interest in the relationship between socioeconomic factors and health outcomes. For example, a search of MEDLINE citations that included one or more of the descriptors "social class, socioeconomic factors, income, or poverty," revealed a level trend at around 120 publications per month.

From the early 1980's onward, there was a dramatic increase in the rate of publication with over 220 per month by June of $2000^{4}$. This $80 \%$ increase is undoubtedly an underestimate as it does not include papers that focus on the links between educational attainment or occupation and health outcomes, and it undoubtedly under represents the literature that is not in English.

While some still dispute the relative importance of health selection on this relationship — sick people drifting downward economically - most believe this is a solid and reproducible finding that calls for attention and remediation. The question then arises as to how one can proceed to reduce inequalities in health. Clearly, the dominant direction in thinking about the cause of disease in contemporary biomedical thinking is focused on very molecular events. The popular and scientific press are replete with arti- 
cles that eagerly herald great breakthroughs in public health, medicine, and biology that will arise from our expanding knowledge in genomics, bioinformatics, and biomedicine. The description of the human genome married with rapid advances in biotechnology are thought by many to presage an era in which many of the major sources of disease and disabilities in world populations will be prevented, delayed, or cured. Without a doubt, the increased knowledge of the molecular basis of the pathobiology of disease portends tremendous advances in our understanding and treatment of disease, but it does not seem likely that this new knowledge will help us understand socioeconomic inequalities in health or to do anything to reduce them. Nor, is it likely to help us understand some of the major public health events of the last century, such as the dramatic loss of life expectancy in countries of Eastern Europe following the break up of the Soviet Union ${ }^{5-7}$. Ironically, many of the new medical discoveries that will come from this knowledge may increase inequalities in health, if the common pattern of new advances being differentially available to those higher placed in society repeats itself.
Instead, the argument can be made for an approach to the understanding, prevention, and reduction of socioeconomic inequalities in health that is portrayed in Figure $1^{8,9}$. In this view, any health phenomena must be understood within a multi-level causal framework, ranging from molecular events within the body to broad features of a society that structures the patterns of exposure to individual and aggregate risks factors, as well as opportunity structures and individual and community resources ${ }^{3,10}$. In what follows, I will illustrate how this framework can be utilized to examine a number of issues that have arisen in the epidemiologic literature on socioeconomic inequalities in health.

\section{Where is the Concentration of Greatest Need Along the Socioeconomic Gradient of Health?}

Much that has been written about socioeconomic inequalities in health has emphasized the graded relationship in socioeconomic position and health, emphasizing that excess risk is found not only among the most

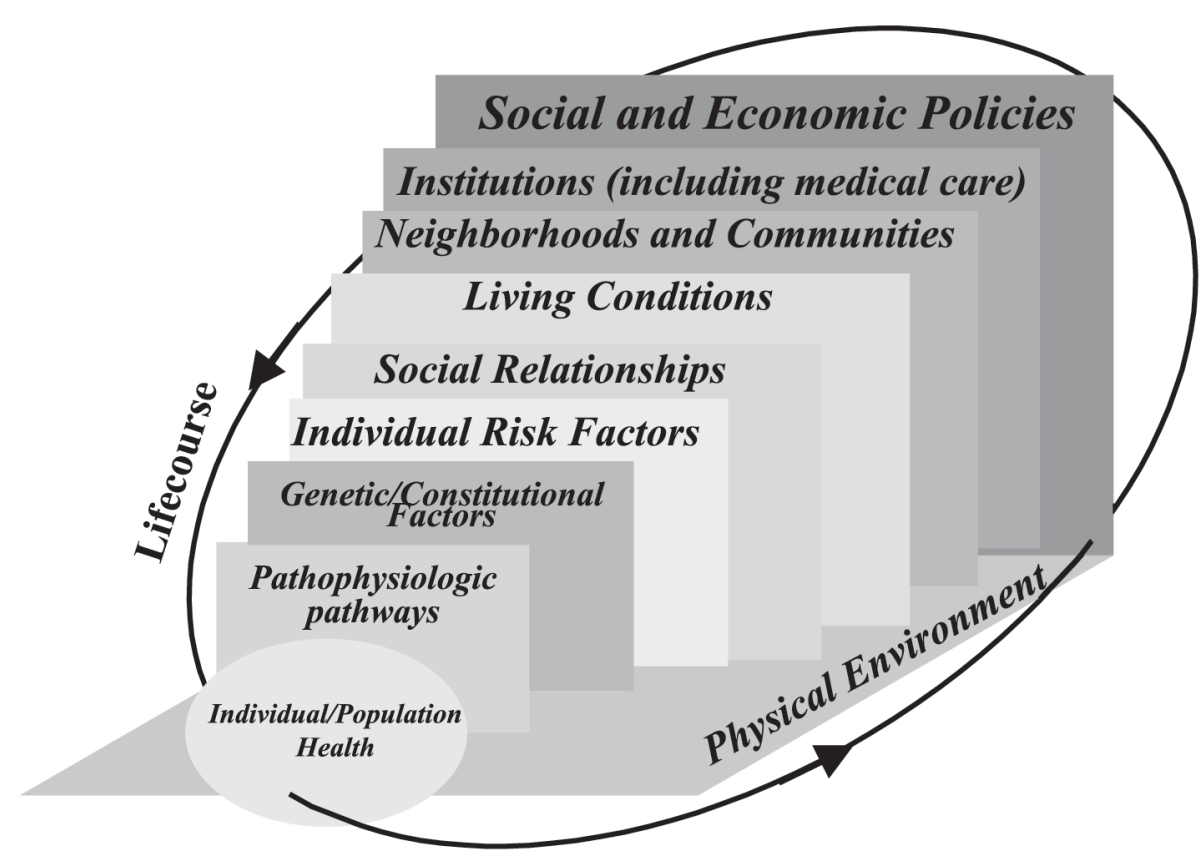

Figure 1 - Multilevel Model of Disease Causation. 
disadvantaged but even among those in relatively privileged positions ${ }^{1,2,11-14}$. While this perspective has been useful in pointing out that socioeconomic factors put more than the very poor at a health disadvantage, a relatively uncritical examination of the shape of this gradient and/or data limitations has tended to leave the reader with a feeling that the relationship between socioeconomic position and risk of poor health or death is linear. The reality is very far from that - at least with respect to the relationship between household income and risk of death. Figure 2 shows how decidedly non-linear the relationship is when examined using the National Longitudinal Mortality Study, a cohort of over one million people whose mortality experience was prospectively examined over almost a decade ${ }^{15}$. As can be seen, the increased risk associated with income differences is greatest among the bottom third of the income distribution and diminishes rapidly with increasing income after that point.

The implications of this non-linearity are that increasing economic resources among those with lower incomes will have the greatest impact on the population's health. (Parenthetically, I know of no careful consideration of how the shape of this curve varies between places or over time. Does, for example, a shift of the income distribution to the right bring the relative risk curve with it, or does it result in decreasing inequalities in health? Because some very wealthy countries still have substantial inequalities in health, this latter possibility seems unlikely.) Figure 2 clearly shows that increasing income improves health the most among approximately the bottom third of the population. Thus, upstream policies that increase the economic resources of the bottom third of the population through employment policies, education and training, or increases in minimum wages or tax credits would theoretically increase the health of that segment of the population and decrease socioeconomic inequalities in health. Similar benefits might accrue from provision or subsidization of childcare or housing costs, or other costs that fall disproportionally on the poor. In the

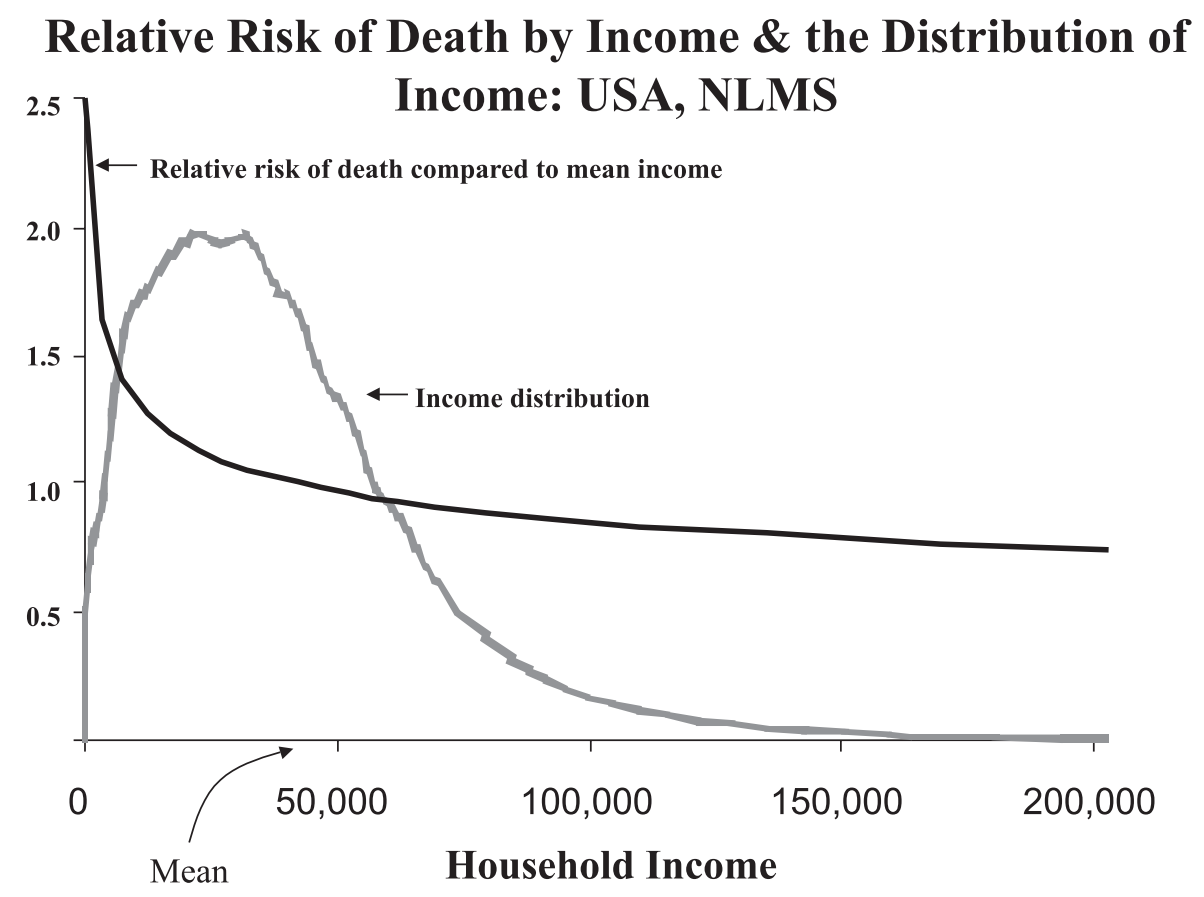

Wolfson, Kaplan,Lynch, Ross, Backlund, BMJ, 1999

Figure 2 - Association between Household Income and Risk of Death. 
United States, and perhaps other countries, poorer working families also have fewer job benefits and greater demands on their out of work time to take care of children and $\mathrm{kin}^{16}$.

\section{Life Course and Cumulative Disadvantage}

A substantial, but contested, literature now documents the impact of prenatal and early life exposures on the later development of poor health, even many decades later ${ }^{17-25}$. Because parental socioeconomic position exquisitely structures exposures to the fetus and the young child, it would not be surprising that socioeconomic inequalities in health occur early in life as well as later ${ }^{26}$. Substantial data now indicates that this is the case, although specific features of the period in which early growth occurs may reduce the impact of early socioeconomic origins ${ }^{26-34}$.

Of course in many cases, socioeconomic origins are often also socioeconomic destinations, and early socioeconomic disadvantage is associated with a cascade of healthdamaging exposures over the life course. A growing amount of evidence now shows that sustained disadvantage is associated with poor health outcomes. For example, Figure 3 illustrates the impact of sustained economic disadvantage from childhood to the $5^{\text {th }}$ and $6^{\text {th }}$ decade of life on level of cognitive function $^{35}$. In this case, a higher score on the cognitive test indicates poorer functioning. The measures of socioeconomic disadvantage are based on childhood, level of education, occupation, and income. Cumulative disadvantage over many decades appears to be associated with worse cognitive function. A similar picture, looking over 29 years, was found when we examined the association between sustained poverty and a wide variety of health outcomes ${ }^{36}$ (Figure 4).

\section{Communities as Crucibles for Growing Health Inequalities}

As the research literature on the socioeconomic position and health has been expanding, so has a related literature indicating that social and economic characteristics of the neighborhoods and communities in which people live are associated with risk of death, morbidity rates, and other outcomes. These two sets of findings fit together nicely because the neighborhoods and communities in which people live are likely to be one

\section{Cognitive Function and Life Course (childhood to adulthood) Socioeconomic Disadvantage}

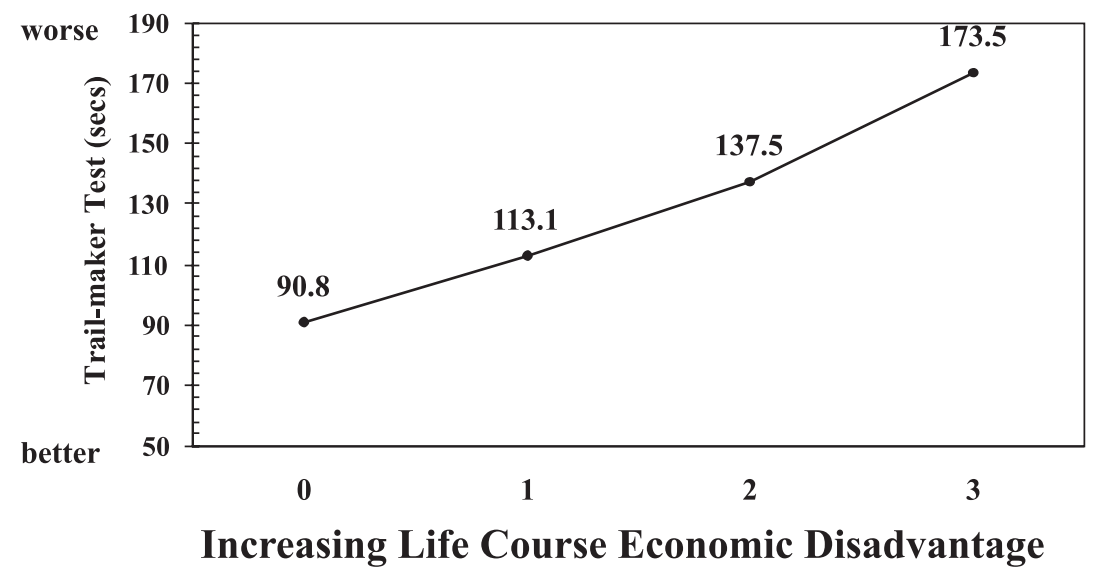

Turrell et al., 2002

Figure 3 - Association between Cumulative Socioeconomic Disadvantage over the Life Course and Performance on the Trail-maker Test. 

on Five Health Outcomes

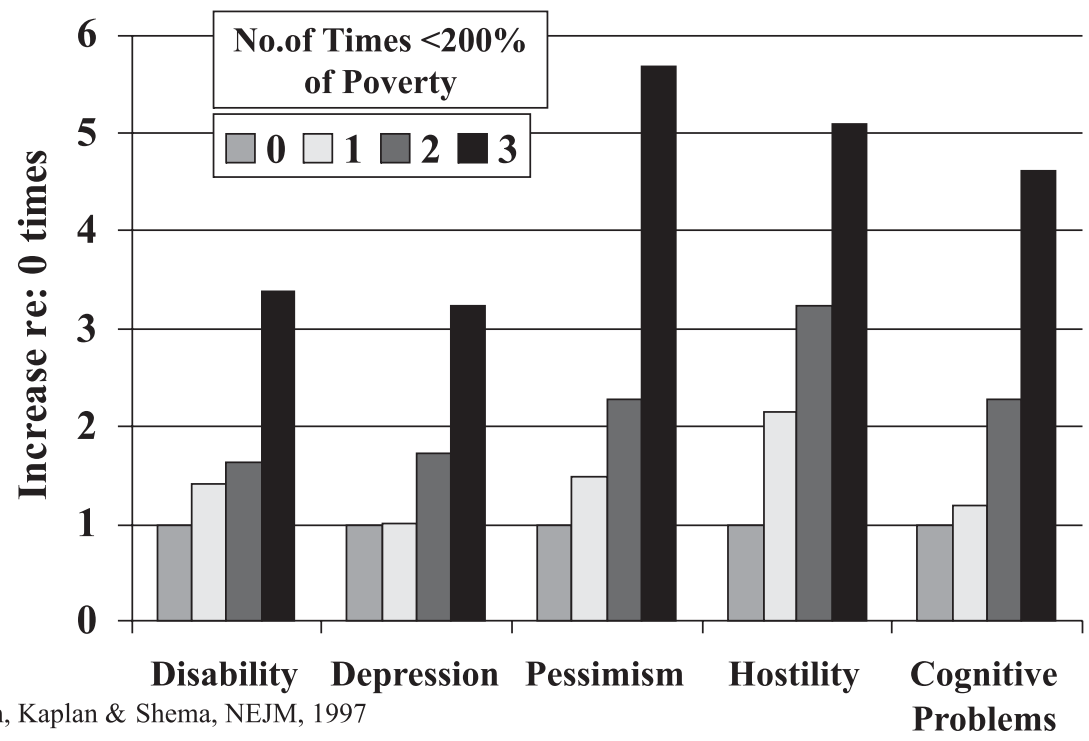

Figure 4 - Cumulative Disadvantage over 29 years and Health Outcomes.

of the important contexts in which socioeconomic inequalities in health are generated. An example of these studies is one we completed a number of years ago. Figure 5 shows the 9-year survival experience of community residents who lived in or outside of areas of high levels of poverty and social disadvantage $\mathrm{e}^{37}$. It is not surprising that

\section{Age-adjusted Survival by Poverty Area Residence: Alameda County Study, 1965-1974}

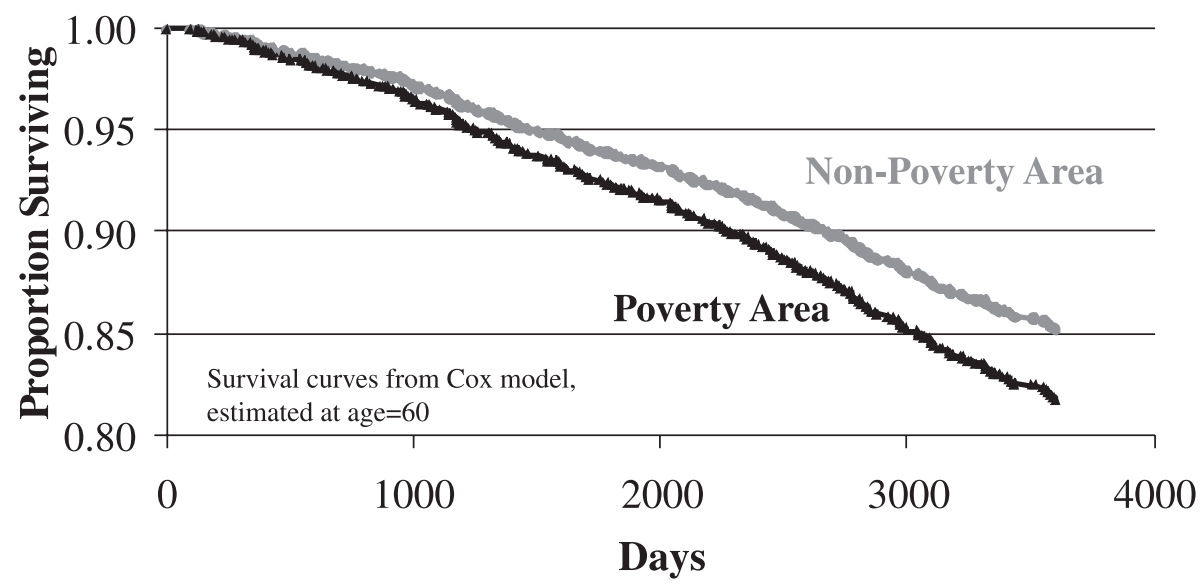

Haan et al., 1987

Figure 5 - Survival by Poverty Area Residence. 
those who lived outside of the poverty area were healthier. After all, they were richer, better educated, more likely to be employed, had better medical care, and differed in many other ways from those who lived in the poverty area. However, when we statistically took all of these differences into account, those who lived in the poverty area still had almost a $50 \%$ increased risk of death. A replication of this study at the national level confirmed our findings, even when there was adjustment for total cholesterol, systolic blood pressure, and a number of other factors, and major cause of death were considered separately $^{38}$. There are now many dozens of studies of this type, and most show these independent effects of area of residence in mortality, morbidity, and chronic disease risk factors; some of them using the most advanced multi-level analytic techniques. Indeed, there is also a large literature showing important effects of neighborhood characteristics on child development, crime, and other outcomes ${ }^{39-41}$.

It seems likely that these effects of place are important in understanding socioeconomic inequalities in health. But, we know little about the ways in which where one lives influences one's health and there is an important need for research in this area. For example, are the influences through differences in material standards of living and institutional resources, differences in exposure to successful or unsuccessful role models, differences in levels of environmental contaminants, stress, or any of many other possibilities—or all of them?

From a multilevel perspective, it makes little sense not to look upstream. For example, zoning and land use policies can, intentionally or unintentionally, structure differential levels of demands and resources according to where one lives. In one study of the area around Atlanta, Georgia, there was an almost 10-fold difference in the per capita tax base. In many places, the differences would be even greater. To the extent that public goods such as education, medical care, policing, and road repair are paid for by taxes, the daily lives of people in these differ- ent areas will differ dramatically, and some of these differences may be important for health.

The levels of resources and strains within a community often represent factors operating outside of that community. For example, closure of a major source of jobs within a community will send economic and social ripples throughout the community, and the resultant social and economic characteristics of that community, and of those who live in it, must be seen as a consequence of those decisions. Again, we see that an understanding of community factors that generate inequalities in health needs to be grounded in an appreciation of the upstream factors that create the community conditions.

\section{Economic Equity and Inequalities in Health}

In many countries over the last two decades, there has been an increase in income and wealth gaps between the rich and poor, and perhaps even an increasingly bifurcated distribution of income. Spearheaded by the work of Wilkinson $^{42,43}$, attention has turned to the impact of inequality in the distribution of income on health and inequalities in health. While the broadest view-that differences in income inequality could explain much of the differences in life expectancy and all cause mortality between developed countries-seems not to be true ${ }^{44}$, there do seem to be some countries in which the inequitable distribution of income within the country is strongly related to geographic health inequalities within the country-the best example being the United States ${ }^{45-47}$. While some have even disputed this relationship, extremely interesting results have emerged when the USA and Canada were compared $^{48}$. Using identical methodologies, a very strong association was observed between the extent of income inequality in US metropolitan areas and age-adjusted mortality, but no such relationship was observed in Canada. Why should there be such a difference in two countries which share many 
features? The answer will depend on how one conceptualizes potential links between income inequality and health ${ }^{44,46,49-51}$. A good argument can be made for the proposition that the effect of income inequality on health reflects a combination of negative exposures and lack of resources held by individuals, along with systematic underinvestment across a wide range of human, physical, health, and social infrastructure. An unequal income distribution is one result of historical, cultural, and political-economic processes. These processes influence the private resources available to individuals and shape the nature of public infrastructure, education, health services, transportation, environmental controls, availability of food, quality of housing, and occupational health regulations that form the "neo-material" matrix of contemporary life. In the US, higher income inequality is significantly associated with many aspects of infrastructure, unemployment, health insurance, social welfare, work disability, educational and medical expenditure, and even library books per capita ${ }^{52}$. Thus, upstream policies can have a major impact on the extent of income inequality within an area or region.

However, to the extent that the links between the distribution of income and the distribution of public and private goods are malleable, the health consequences of inequity in the income distribution can be mitigated. There is good reason to believe that variations between the US and Canada with respect to taxation and transfers, economic and racial segregation, and other factors result in there being a link between within country income inequality and health for the US and no such link for Canada.

\section{Globalization and Health Inequalities}

It is impossible to talk about health inequalities without considering the global situation and global health inequalities. WHO reports demonstrate dramatically the enormous variations in the likelihood of good health and development between peoples of poor, moderate, and high income countries, and per capita GDP is strongly associated with life expectancy below $\$ 10,000$ or so per capita GDP. According to the World Bank, over one billion people ( $20 \%$ of world's population) are estimated to live on less than $\$ 1$ per day, and 3 billion ( $49 \%$ of world's population) on less than $\$ 2$ per day. More than 110 million primary school age children are out of school (60\% of them girls) and many more live without adequate food, shelter, safe water, and sanitation ${ }^{53}$. It is easy to understand how this situation can result in a tremendous burden of disease and premature disability and mortality, but it is difficult from the numbers alone to comprehend the magnitude of the problem. The overall pattern of results suggests that with development may come increasing gaps between the rich and poor, with many being left behind in a worse state $\mathrm{e}^{54}$. While the role of globalization in these changes may be hotly debated, there is some evidence that global economic crises can have substantial effects on health and social factors associated with increased health risks. For example, the impact of the 1998 Asian financial crisis in Thailand included increases in poverty, unemployment, divorce rates, crime, child abandonment, and drug use ${ }^{55}$. Similarly, it does not take a great deal of imagination to translate the decreases in the rates of expenditure on public health associated with increasing debt burden to a deterioration in overall health status and a rise in health inequalities. For example, in Pakistan in the 1990's, expenditures on debt service increased 7-fold to 350 billion Pakistani rupees, while the National health budget stagnated at around 25 billion, well less than $10 \%$ of that spent of debt service, and health research expenditures dropped to essentially zero rupees ${ }^{56}$.

A truly global perspective situates these health and wealth inequalities within forces operating in the global economy. While there is an empirical base for making sound inferences about the global patterns connecting health and wealth in one place with that in another, it is possible to engage in the type of data-based speculation portrayed in Figure 
6, which links global economic forces with deforestation, destruction of traditional agriculture, development of urban centers with concentrated poverty, decline in traditional social and behavioral patterns, and the subsequent development of transitions in health profiles with increasing rates of cardiovascular disease. All the while this is happening the same forces can be seen to be connected to economic insecurity, life-style changes including massive increases in fast food consumption, and the development of low paid jobs to supply the fast food industry ${ }^{10}$. Of course it is difficult to document every one of these links. This difficulty presents a challenge to epidemiologists and other scientists to develop data sources and analytic tools to document these etiologic forces with the same zeal as is addressed to the development of new molecular technology.

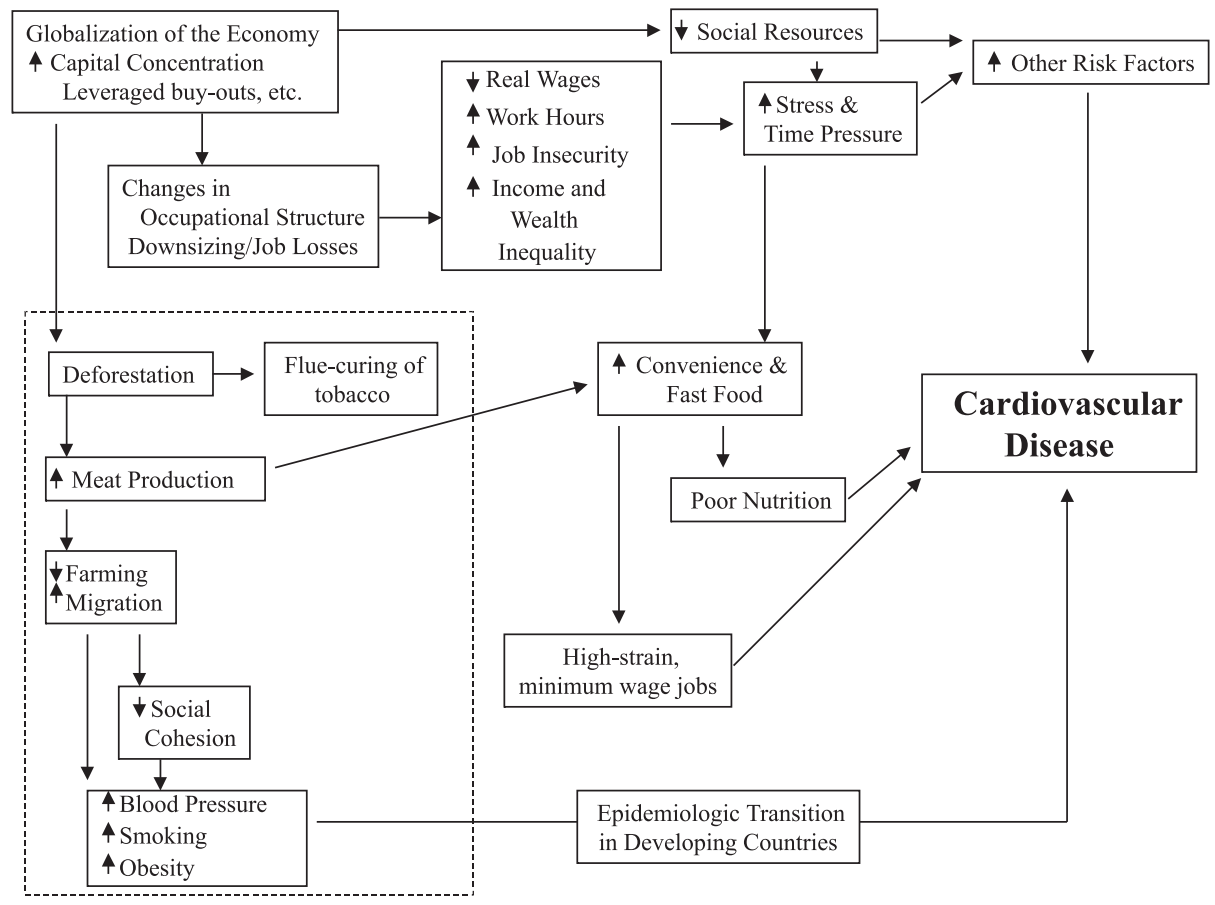

Figure 6 - Connections between the Global Economy and Health in Poor and Wealthy Countries.

\section{References}

1. Kaplan GA, Haan MN, Syme SL, Minkler M, Windleby M. Socioeconomic status and health. In: Amler RW, Dull HB (eds.). Closing the gap: the burden of unnecessary illness. New York: Oxford University Press, 1987, p. 125-9.

2. Haan MN, Kaplan GA, Syme SL. Socioeconomic status and health: old observations and new thoughts. In: Bunker JP, Gomby DS, Kehrer BH (eds.). Pathways to health: the role of social factors. Menlo Park: Henry J. Kaiser Family Foundation, 1989, p. 76-135.
3. Lynch JW, Kaplan GA. Socioeconomic position. In: Berkman LF, Kawachi I (eds.). Social Epidemiology. New York: Oxford University Press, 2000, p. 13-35.

4. Kaplan GA, Lynch JW. Whither studies on the socioeconomic foundations of population health? (Editorial). Am J Public Health 1997; 87: 1409-11.

5. Walberg P et al. 1998. Economic change, crime, and mortality crisis in Russia: a regional analysis. $\mathrm{Br} \mathrm{Med} \mathrm{J}$ 1998; 317: 312-8. 
6. Chenet L, McKee M, Fulop N, Bojan F, Brand H, Hort A, Kalbarczyk P. Changing life expectancy in central Europe: is there a single reason? J Public Health Med 1996; 18: 329-36.

7. Leon DA et al. Huge variation in Russian mortality rates 1984-1994: artefact, alcohol, or what? Lancet 1997; 350: 383-8.

8. Kaplan GA. 1999. What is the role of the social environment in understanding inequalities in health? Ann N Y Acad Sci 1999; 89: 116-9.

9. Kaplan GA. Upstream and downstream approaches to inequalities in health. http://www.sph.umich.edu/ miih/index2.html, working papers and publications; 1999.

10. Kaplan GA, Lynch JW. Socioeconomic considerations in the primordial prevention of cardiovascular disease. Prev Med 1999; 29: S30-S35.

11. Syme SL, Berkman LF. Social class, susceptibility and sickness. Am J Epidemiol 1976; 104: 1-8.

12. Adler NE et al. Socioeconomic status and health. The challenge of the gradient. Am Psychol 1994; 49: 15-24.

13. Evans RG, Barer ML, Marmor TR. Why Are Some People Healthy and Others Not? New York: Aldine de Gruyter; 1994.

14. Marmot MG et al. Health inequalities among British civil servants: the Whitehall II study. Lancet 1991; 337: 1387-93. Notes: Comment in: Lancet 1991 Jul 6; 338(8758): 58-9.

15. Wolfson $\mathrm{M}$ et al. Relation between income inequality and mortality: empirical demonstration. Br Med J 1999; 319: 953-7.

16. Heymann SJ. The Widening Gap: Why American Working Families are in Jeopardy and What Can Be Done About It. New York: Basic Books; 2000.

17. Forsén T et al. Mother's weight in pregnancy and coronary heart disease in a cohort in Finnish men: follow up study. Br Med J 1997; 315: 837-40.

18. Osmond $\mathrm{C}$ et al. Early growth and death from cardiovascular disease in women. Br Med J 1993; 307: 1519-24.

19. Phillips DIW. The 'fetal origins' hypothesis: role of programming of adrenocortical and sympathoadrenal function. In: O'Brien PMS, Wheeler T, Barker DJP (eds.). Fetal programming : influences on development and disease in later life. London: RCOG Press; 1999, p. 414-21.

20. Barker DJP. Fetal nutrition and cardiovascular disease in later life. Br Med Bull 1997; 53: 96-108.

21. Susser M, Levin B. Ordeals for the fetal programming hypothesis. Br Med J 1999; 318: 885-6.
22. Paneth N, Susser M. Early origin of coronary heart disease (the "Barker hypothesis"). Br Med J 1995; 310: 411.

23. Keating DP, Hertzman C. Developmental health and the wealth of nations: social, biological, and educational dynamics. New York: Guilford Press; 1999.

24. Kuh D, Ben-Schlomo Y. A lifecourse approach to chronic disease epidemiology. Oxford: Oxford University Press; 1997.

25. Aboderin I et al. Life Course Perspectives on Coronary Heart Disease, Stroke and Diabetes. The Evidence and Implications for Policy and Research. Geneva: World Health Organization; 2002.

26. Lynch JW, Kaplan GA, Salonen JT. Why do poor people behave poorly? Variation in adult health behaviours and psychosocial characteristics by stages of the socioeconomic lifecourse. Soc Sci Med 1997; 44: 809-19.

27. Davey Smith G, Ben-Shlomo Y, Lynch JW. Lifecourse approaches to inequalities in coronary heart disease risk. In: Stansfeld S, Marmot M (eds.). Stress and Heart Disease. London: B M J Books; 2001.

28. Gunnell DJ et al. Lifecourse exposure and later disease: a follow-up study based on a survey of family diet and health in pre-war Britian (1937-1939). Public Health 1996; 110: 85-94.

29. Hertzman C, Power C, Matthews S, Manor O. Using an interactive framework of society and lifecourse to explain self-rated health in early adulthood. Soc Sci Med 2001; 53: 1575-85.

30. Davey Smith G et al. Socioeconomic position over the lifecourse and mortality. Br Med J (submitted).

31. Davey Smith G, Gunnell D, Ben-Shlomo Y. Lifecourse approaches to socioeconomic differentials in causespecific adult mortality. In: Leon D, Walt G (eds.). Poverty, Inequality and Health: An International Perspective. Oxford: Oxford University Press; 2001. p. 88-124.

32. Davey Smith G, Ben-Shlomo Y, Lynch JW. Lifecourse approaches to inequalities in coronary heart disease risk. In: Stansfeld S, Marmot M (eds.) Stress and Disease. London: B M J Books; 2001. (in press)

33. Lynch JW et al. Childhood and adult socioeconomic status as predictors of mortality in Finland. Lancet 1994; 343: 524-7. Notes: Comment in: Lancet 1994 Feb 26; 343(8896): 496; Comment in: Lancet 1994 May 14; 343(8907): 1224-5.

34. Kaplan GA et al. Childhood socioeconomic position and cognitive function in adulthood. Int $J$ Epidemiol 2001; 30: 256-63.

35. Turrell G et al. Socioeconomic position across the lifecourse and cognitive function in late middle age. $J$ Gerontol B Psychol Sci Soc Sci 2002; 57: S43-S51. 
36. Lynch JW, Kaplan GA, Shema SJ. Cumulative impact of sustained economic hardship on physical, cognitive, psychological, and social functioning. $N$ Engl J Med 1997; 337: 1889-95.

37. Haan MN, Kaplan GA, Camacho T. Poverty and health: prospective evidence from the Alameda County Study. Am J Epidemiol 1987; 125: 989-98.

38. Waitzman NJ, Smith KR. Phantom of the area: povertyarea residence and mortality in the United States (Note: published erratum appears in Am J Public Health 1998; 88(7): 1122). Am J Public Health 1998; 88: 973-6.

39. Brooks-Gunn J, Duncan GJ, Aber JL. Neighborhood poverty: Context and consequences for children. Vols, 1 \& 2. New York: Russell Sage; 1997.

40. Sampson RJ, Wilson WJ. Toward a theory of race, crime, and urban inequality. In: Hagan J, Peterson (eds.). Crime and Inequality. Stanford: Stanford University Press; 1995, p. 37-54.

41. Sampson RJ, Raudenbush SW, Earls F. Neighborhoods and violent crime: a multilevel study of collective efficacy. Science 1997; 277: 918-24.

42. Wilkinson RG. Income distribution and life expectancy. Br Med J 1992; 304: 165-8.

43. Wilkinson RG. Unhealthy societies. In: (monograph.) The afflictions of inequality, London: Routledge; 1996.

44. Lynch JWI et al. Income inequality, the psychosocial environment and health: comparisons of wealthy nations. Lancet 2001; 358: 194-200.

45. Lynch JW et al. Income inequality and mortality in metropolitan areas of the United States. Am J Public Health 1998; 88: 1074-80.

46. Kaplan GA et al. Inequality in income and mortality in the United States: analysis of mortality and potential pathways. Br Med J 1996; 312: 999-1003.
47. Kennedy BP, Kawachi I, Prothrow-Stith D. Income distribution and mortality: cross-sectional ecological study of the Robin Hood index in the United States. $\mathrm{Br}$ Med J 1996; 312: 1004-7.

48. Ross NA et al. Relation between income inequality and mortality in Canada and the United States: a crosssectional assessment using Census data and vital statistics. Br Med J 2000; 320: 898-902.

49. Lynch JW, Davey Smith G, Kaplan GA, House JS. Income inequality and mortality: importance to health of individual income, psychosocial environment, or material conditions. Br Med J 2000; 320: 1200-4.

50. Lynch JW, Kaplan GA. Understanding how inequality in the distribution of income affects health. $J$ Health Psychol 1997; 2: 297-314.

51. Kaplan GA, Lynch JW. Is economic policy health policy? Editorial. Am J Public Health 2001; 91: 351-3.

52. Lynch JW, Davey Smith G, Kaplan GA, House JS. Income inequality and health: a neomaterial interpretation. Br Med J. (in press)

53. World Bank. Global Poverty Report. http:// www.worldbank.org/html/extdr/extme/ G8_poverty2000.pdf; 2000.

54. Wagstaff A. Inequalities in Health in Developing Countries: Swimming Against the Tide? http:// econ.worldbank.org/files/12290_wps2795.pdf;

55. Shivakumar J. Thailand's Response to AIDS: Building on Success, Confronting the Future. http:// www.worldbank.or.th/social/index.html; 2001.

56. Bhutta ZA. Why has so little changed in maternal and child health in south Asia? Br Med J 2000; 321: 809-12. 